\title{
Which biologic valve should we select for the 45 - to 65-year-old age group requiring aortic valve replacement?
}

\author{
F. Dagenais, MD, P. Cartier, MD, ${ }^{\dagger}$ P. Voisine, MD, D. Desaulniers, MD, J. Perron, MD, R. Baillot, MD, G. Raymond, MD, \\ J. Métras, MD, D. Doyle, MD, and P. Mathieu, MD
}

From the Department of Cardiac Surgery, Laval Hospital, Quebec City, Quebec, Canada.

Read at the Thirtieth Annual Meeting of The Western Thoracic Surgical Association, Maui, Hawaii, June 23-26, 2004.

Received for publication July 2, 2004; revisions received Oct 12, 2004; accepted for publication Oct 21, 2004.

Address for reprints: Francois Dagenais, Department of Cardiac Surgery, Laval Hospital, 2725 chemin Sainte-Foy, Sainte Foy, Québec, Canada, G1V 4G5 (E-mail: francois.dagenais@chg.ulaval.ca).

$\dagger$ Deceased.

J Thorac Cardiovasc Surg 2005;129:1041-9 $0022-5223 / \$ 30.00$

Copyright $\odot 2005$ by The American Association for Thoracic Surgery

doi:10.1016/j.jtcvs.2004.10.041
Objective: The diversity of biologic valves available to replace the aortic valve renders selection difficult for the 45- to 65-year-old patient. To evaluate and compare the results of biologic valves in the 45- to 65-year-old patient, we reviewed our experience (1991-2004).

Methods: Three hundred thirty-two patients between 45 and 65 years old with isolated aortic valve disease had a biologic valve implanted: Freestyle valve in 140 patients, a homograft in 54 patients, a stented Mosaic or Perimount valve (stented xenograft) in 62 patients, and a Ross procedure in 76 patients.

Results: Perioperative mortality was comparable for all groups (Freestyle, 2.1\%; homograft, $3.7 \%$; stented xenograft, $3.2 \%$; Ross procedure, $1.3 \% ; P=.8$ ). Echocardiographically determined valve performance at discharge was significantly enhanced in the Ross procedure and homograft groups (indexed effective orifice area: Freestyle, $0.9 \pm 0.3 \mathrm{~cm}^{2} / \mathrm{m}^{2}$; homograft, $1.3 \pm 0.3 \mathrm{~cm}^{2} / \mathrm{m}^{2}$; stented xenograft, $0.8 \pm 0.2 \mathrm{~cm}^{2} / \mathrm{m}^{2}$; Ross procedure, $1.4 \pm 0.4 ; P<.0001 ;$ mean gradient: Freestyle, $12.0 \pm 6.6 \mathrm{~mm} \mathrm{Hg}$; homograft, $7.4 \pm 4.0 \mathrm{~mm} \mathrm{Hg}$; stented xenograft, $15.4 \pm 5.4 \mathrm{~mm}$ $\mathrm{Hg}$; Ross procedure, $4.6 \pm 3.2 \mathrm{~mm} \mathrm{Hg} ; P<.0001)$. For all yearly follow-up, freedom from New York Heart Association class III or IV was comparable and greater than $95 \%$ for all groups. At 7 years, cardiac survival (homograft, 96.3\% \pm $3.7 \%$; Ross procedure, $90.6 \% \pm 6.3 \%$; stented xenograft, $86.0 \% \pm 10.3 \%$; Freestyle, $89.2 \% \pm 10.8 \% ; P=.7$ ) and freedom from reoperation (Ross procedure, $98.5 \% \pm 1.4 \%$; homograft, $90.6 \% \pm 5.7 \%$; Freestyle, $88.0 \% \pm 4.9 \%$; stented xenograft, $90.0 \% \pm 8.0 \% ; P=.4$ ) were comparable. Freedoms from significant bleeding events, valve-related neurologic events, or endocarditis were comparable and greater than $95 \%$ for all groups.

Conclusion: Type of aortic biologic valve for the 45- to 65-year-old patient does not affect midterm survival or valve-related morbidity. Thus the choice of biologic valve for the 45- to 65-year-old patient should be dictated by patient-surgeon preference, ease of implantation, and reoperation until longer comparative studies are available.

$\mathrm{T}$ he incidence of aortic valve replacement is increasing, mainly because of population aging. Moreover, congenital aortic valve disease remains a common indication for aortic valve replacement in the current era of cardiac surgery. Selection of valve type for aortic valve replacement depends on many factors, such as the patient's age, life expectancy, valve durability, and anticoagulation-related issues. Within the pediatric age group, the Ross procedure has gained popularity, especially because of the autograft's capacity to enlarge with patient growth. ${ }^{1}$ Excellent durability and hemodynamic performance with acceptable valve-related morbidity have been reported for pediatric patients undergoing a Ross procedure. ${ }^{2,3}$ On the other hand, mechanical valves, 
TABLE 1. Patient characteristics $(n=332)$

\begin{tabular}{lccccc}
\hline & $\begin{array}{c}\text { Freestyle } \\
(\mathbf{n}=\mathbf{1 4 0})\end{array}$ & $\begin{array}{c}\text { Homograft } \\
(\mathbf{n}=\mathbf{5 4})\end{array}$ & $\begin{array}{c}\text { Mosaic + Perimount } \\
(\mathbf{n}=\mathbf{6 2})\end{array}$ & $\begin{array}{c}\text { Ross } \\
(\mathbf{n}=\mathbf{7 6})\end{array}$ & $\boldsymbol{P}$ value \\
\hline Age (y) & $59.0 \pm 5.1$ & $53.5 \pm 5.9$ & $61.0 \pm 4.0$ & $51.1 \pm 3.6$ & $<.0001$ \\
Sex (\% male) & 57.9 & 63.0 & 67.7 & 56.6 & .50 \\
Diabetes (\%) & 15.7 & 7.4 & 17.7 & 6.6 & .09 \\
BMI >30 (\%) & 28.6 & 24.1 & 33.9 & 29.3 & .71 \\
CVA (\%) & 5.0 & 9.3 & 8.1 & 2.6 & .34 \\
Vascular disease (\%) & 4.3 & 16.7 & 8.2 & 6.6 & .03 \\
HBP (\%) & 40.0 & 40.7 & 41.9 & 27.6 & .23 \\
Current smoker (\%) & 14.0 & 17.3 & 21.3 & 24.0 & .29 \\
COPD (\%) & 17.1 & 9.4 & 17.7 & 7.9 & .16 \\
AF (\%) & 5.7 & 7.4 & 0.0 & 1.3 & .08 \\
Parsonnet score (mean) & $8.1 \pm 6.5$ & $9.0 \pm 7.3$ & $10.1 \pm 9.5$ & $6.6 \pm 6.5$ & .12 \\
\hline BM, Bod mas
\end{tabular}

$B M I$, Body mass index; $C V A$, cerebrovascular accident; $H B P$, high blood pressure; $C O P D$, chronic obstructive pulmonary disease; $A F$, atrial fibrillation.

either unileaflet tilting discs or bileaflet discs, show excellent durability in the young and middle-aged population. ${ }^{4,5}$ However, mechanical valve replacement exposes the patient to the cumulative risks of lifelong anticoagulation. On the contrary, biologic aortic valve substitutes have traditionally been shown to be more prone to structural valve deterioration in the younger age groups. ${ }^{6,7}$ However, the excellent long-term outcomes reported with biologic valves in patients older than 65 years coupled with the lower operative mortality for reoperative prosthetic aortic valve failure increase interest in comparing outcomes of current biologic valves in the middle-aged adult. The present report aims to compare midterm outcomes of currently available biologic aortic valve substitutes (aortic homograft, Ross procedure, stentless xenograft, and stented xenograft) for 45- to 65-year-old patients requiring aortic valve replacement.

\section{Methods}

\section{Patient Population}

Between September 1991 and April 2004, 332 patients aged between 45 and 65 years underwent a biologic aortic valve replacement at the Québec Heart Institute: a Ross procedure in 76 pa- tients, a Freestyle valve in 140 patients, a stented xenograft in 62 patients, and an aortic homograft in 54 patients. During the same period, 3336 patients underwent aortic valve replacement in our institution. Decisions to implant a biologic valve at a younger age, as well as the type of biologic valve selected, were left to surgeonpatient preference. During the same time interval, 257 mechanical aortic valves were implanted in patients aged 45 to 65 years. No patient had significant coronary artery disease requiring coronary artery bypass grafting to limit the effect of ischemic disease on outcome. Patient characteristics are listed in Table 1. Mean age at valve implantation was significantly lower in the homograft and Ross groups. A trend toward a lower comorbid profile was observed in the Ross group, as suggested by a lower mean Parsonnet score.

\section{Valve Substitute and Surgical Technique}

All homografts were harvested locally within 24 hours after donor death. Valves were subsequently shipped to Cryolife Inc (Marietta, $\mathrm{Ga}$ ) and cryopreserved according to the company's protocol on the basis of liquid nitrogen freezing in an antibiotic and dimethyl sulfoxide solution. Homografts were used in a root configuration in $85.2 \%$ of patients and with a scalloped subcoronary implantation technique in $14.8 \%$ of patients. Selection of the size of the pulmonary homograft for the Ross procedure was based on the largest

TABLE 2. Perioperative data $(\mathbf{n}=332)$

\begin{tabular}{lccccc}
\hline & $\begin{array}{c}\text { Freestyle } \\
(\mathbf{n}=\mathbf{~ 4 0 )}\end{array}$ & $\begin{array}{c}\text { Homograft } \\
(\mathbf{n}=\mathbf{5 4})\end{array}$ & $\begin{array}{c}\text { Mosaic + Perimount } \\
(\mathbf{n}=\mathbf{6 2})\end{array}$ & $\begin{array}{c}\text { Ross } \\
(\mathbf{n}=\mathbf{7 6})\end{array}$ & $\boldsymbol{P}$ value \\
\hline CPB time (min) & $122.6 \pm 32.5$ & $124.2 \pm 33.8$ & $90.0 \pm 32.1$ & $146.0 \pm 33.7$ & $<.0001$ \\
Crossclamp time (min) & $94.7 \pm 22.8$ & $93.3 \pm 25.1$ & $66.9 \pm 25.2$ & $112.9 \pm 25.9$ & $<.0001$ \\
Prolonged intubation (\%) & 2.1 & 5.6 & 9.7 & 0.0 & .01 \\
Renal failure (\%) & 4.3 & 0.0 & 4.8 & 4.0 & .48 \\
Mediastinitis (\%) & 0.0 & 0.0 & 1.6 & 0.0 & .23 \\
Septicemia (\%) & 0.7 & 0.0 & 1.6 & 2.7 & .50 \\
Length of stay (d) & $8.4 \pm 4.5$ & $8.9 \pm 8.2$ & $8.0 \pm 5.1$ & $8.0 \pm 4.4$ & .79 \\
Observed mortality (\%) & 2.1 & 3.7 & 3.2 & 1.3 & .80 \\
\hline
\end{tabular}

$C P B$, Cardiopulmonary bypass. 


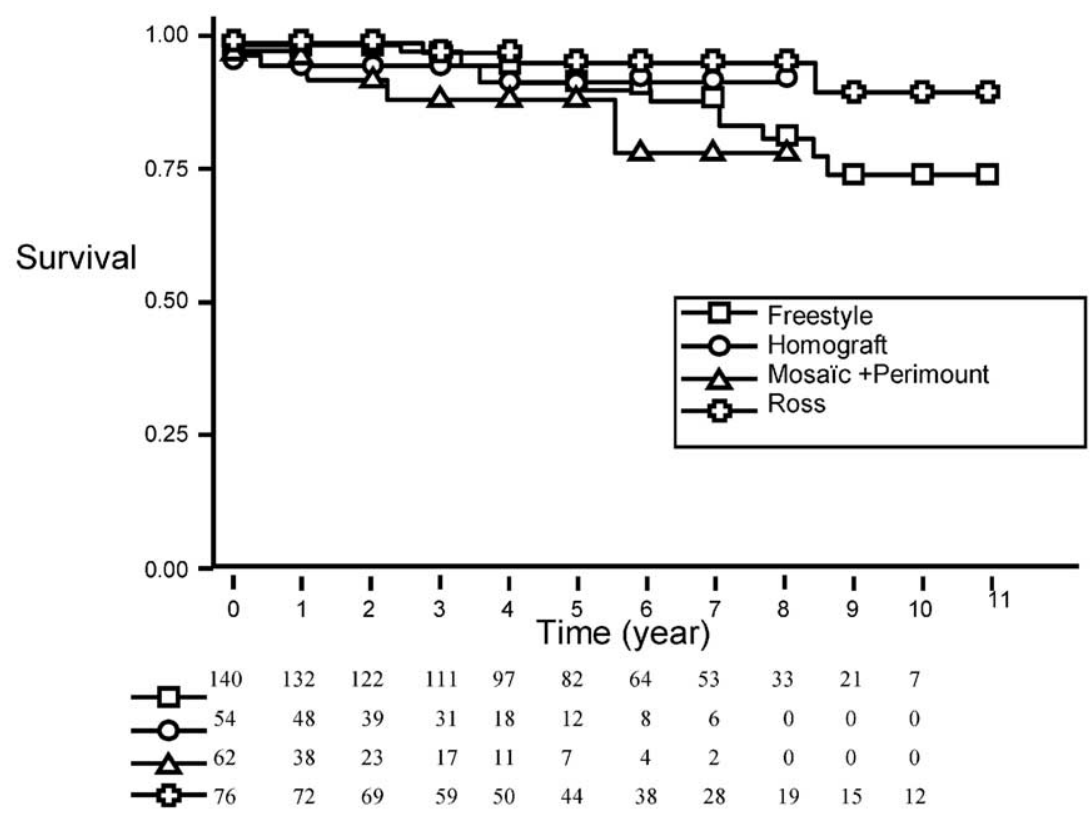

Figure 1. Freedom from all death.

available graft on the shelf. Presence of a root annuloectasia or a significant anomaly of the pulmonic valve is considered a contraindication to proceed with the Ross procedure in our institution. Freestyle (Medtronic Inc, Minneapolis, Minn) valves were implanted mainly by using a freehand subcoronary technique (78.6\%). The noncoronary sinus was not scalloped in the majority of patients with the subcoronary technique. A root configuration was used in $21.4 \%$ of cases, mainly in patients with aortic root disease. Stented xenografts used were either the Mosaic valve in $66 \%$ of cases (Medtronic) or the Perimount valve in $34 \%$ of cases (Edwards, Irvine, Calif). All operations were conducted during cardiopulmonary bypass with moderate hypothermia. Although implantation techniques were standard among surgeons, myocardial preservation techniques varied among surgeons.

\section{Follow-up and Statistics}

All surviving patients were assessed by means of echocardiography before hospital discharge. Follow-up was 100\% complete. Mean follow-up was $4.7 \pm 2.9$ years for the whole cohort, $5.4 \pm$ 2.9 for the Freestyle group, $4.0 \pm 2.3$ for the homograft group, 2.7 \pm 2.1 for the stented xenograft group, and $5.6 \pm 3.1$ for the Ross group. Patients were followed at the Laval Hospital Cardiac Surgery Valve Clinic. Every other year, all patients had a clinical evaluation by the operating surgeon and underwent echocardiography. In years without clinical visits, the patient was contacted by telephone and evaluated by the same clinical research nurse according to a standard questionnaire. All hospitalization records were prospectively collected during the follow-up period. Valverelated morbidity and mortality were recorded according to previously published guidelines and collected prospectively. ${ }^{8}$ All deaths were thoroughly investigated through hospitalization records or autopsy reports. Cardiac-related mortality was defined as all valverelated and unrelated cardiac events, including unexplained deaths.
Results of quantitative and nominal variables were expressed as means \pm SD and percentages, respectively. One-way analysis of variance was performed to carry out analyses for comparisons between groups. The normality assumption was verified with the Shapiro-Wilk test. The Brown and Forsythe variation and the Levene test were used to verify the homogeneity of variances. When these assumptions were not fulfilled, an alternative procedure independent of these assumptions was done. The procedure performed was to replace the observations by their rank (ie, rank transformation) and to apply the ordinary $\mathrm{F}$ test from 1-way analysis of variance. This technique is an approximate procedure, but one that has good statistical properties when compared with the Kruskal-Wallis test. Posteriori comparisons were performed by using the Tukey technique. Categoric variables were analyzed with Fisher exact tests. Product-limit analyses (also called KaplanMeier analyses) were performed to examine the time-dependent cumulative probabilities of the outcomes. The plots of the negative $\log$ of the survival function versus time revealed that exponential models were not appropriate for the survival data. Consequently, the $\log$ rank tests with associated $\chi^{2}$ tests were used to test the hypothesis that there was no difference in survival functions between both groups. The data were analyzed with the statistical package program SAS (SAS Institute Inc., Cary, NC).

\section{Results \\ Perioperative Data}

Perioperative data are shown in Table 2. Aortic crossclamp and cardiopulmonary bypass times were significantly lower in the stented xenograft group. Perioperative morbidity was low and comparable for all groups other than a significantly higher incidence of prolonged intubation in the stented xenograft group. The hospital mortality was slightly higher, albeit non- 




significant, in the stented xenograft and homograft groups. At discharge, transthoracic echocardiography showed a significantly enhanced valve performance in the homograft and Ross groups compared with the Freestyle and stented xenograft groups (indexed effective valve orifice area: Freestyle, $0.9 \pm$ $0.3 \mathrm{~cm}^{2} / \mathrm{m}^{2}$; homograft, $1.3 \pm 0.3 \mathrm{~cm}^{2} / \mathrm{m}^{2}$; stented xenograft, $0.8 \pm 0.2 \mathrm{~cm}^{2} / \mathrm{m}^{2}$; Ross procedure, $1.4 \pm 0.4 \mathrm{~cm}^{2} / \mathrm{m}^{2} ; P<$ .0001 , mean gradient: Freestyle, $12.0 \pm 6.6 \mathrm{~mm} \mathrm{Hg}$; homograft, $7.4 \pm 4.0 \mathrm{~mm} \mathrm{Hg}$; stented xenograft, $15.4 \pm 5.4 \mathrm{~mm}$ $\mathrm{Hg}$; Ross procedure, $4.6 \pm 3.2 \mathrm{~mm} \mathrm{Hg} ; P<.0001)$.
Figure 2. Freedom from cardiac death.

\section{Survival and Valve-Related Morbidity}

Data on survival and valve-related morbidity are shown in Figures 1 through 3 . At 7 years, a lower actuarial overall survival was observed in the Freestyle and stented xenograft groups compared with that in the Ross group, although this difference was nonsignificant (Freestyle, 79.8\% $\pm 4.3 \%$; homograft, $83.9 \% \pm 6.2 \%$; stented xenograft, $76.4 \% \pm$ $11.0 \%$; Ross procedure, $91.8 \% \pm 4.4 \%$; stented xenograft vs Ross procedure, $P=.14$; Freestyle vs Ross procedure, $P$ $=.26$; Figure 1).

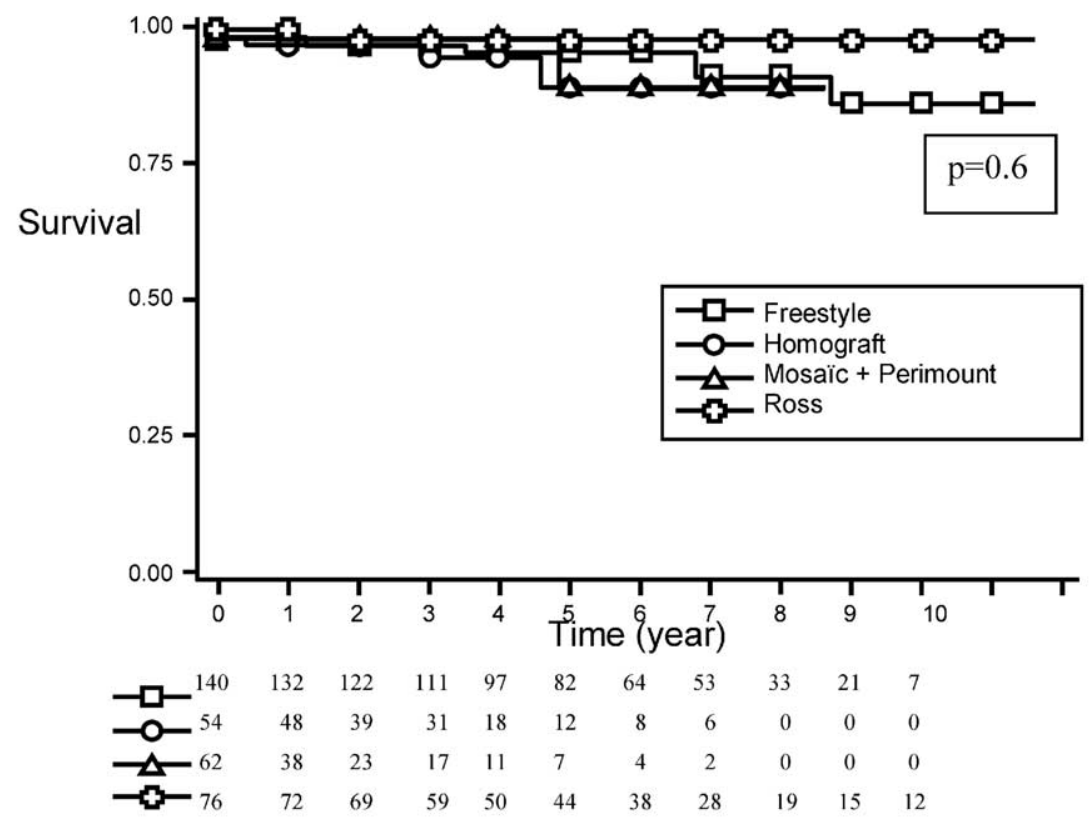

Figure 3. Freedom from reoperation. 
Among the 32 deaths registered during follow-up, 18 were of noncardiac cause; of these, 11 were encountered in the Freestyle group. When assessing cardiac survival, actuarial survival curves were similar for all groups at 7 years (homograft, 96.3\% $\pm 3.7 \%$; Ross procedure, $90.6 \% \pm$ 6.3\%; stented xenograft, $86.0 \% \pm 10.3 \%$; Freestyle, $89.2 \%$ $\pm 10.8 \% ; P=.7$; Figure 2). Among the 14 cardiac deaths, 5 were valve related (Freestyle, 2; Ross procedure, 2; stented xenograft, 1 ; homograft, $0 ; P=$ not significant), 1 death in the Freestyle group remained unexplained, and 8 cardiac deaths were not valve related (Freestyle, 3; homograft 2; stented xenograft, 2; Ross procedure, 1; $P=$ not significant). Freedom from valve endocarditis (Freestyle, $97.4 \% \pm 2.0 \%$; homograft, $97.7 \% \pm 2.2 \%$; stented xenograft, $98.3 \% \pm 1.7 \%$; Ross procedure, $100 \% \pm 0 \% ; P=$ .6), valve-related thromboembolism (Freestyle, 97.7\% \pm 1.3\%; homograft, $100 \% \pm 0 \%$; stented xenograft, $100 \% \pm$ $0 \%$; Ross procedure, $100 \% \pm 0 \% ; P=.3$ ), severe bleeding (Freestyle, 95.4\% \pm 2.0\%; homograft, $96.0 \% \pm 2.8 \%$; stented xenograft, $98.3 \% \pm 1.7 \%$; Ross procedure, $100 \% \pm$ $0 \% ; P=.4$ ), and hemolysis (Freestyle, $100 \% \pm 0 \%$; homograft, $100 \% \pm 0 \%$; stented xenograft, $100 \% \pm 0 \%$; Ross procedure, $100 \% \pm 0 \%$ ) were comparable at 7 years for all groups.

Figure 3 demonstrates a similar incidence of reoperation (Ross procedure, $98.5 \% \pm 1.4 \%$; homograft, $90.6 \% \pm$ 5.7\%; Freestyle, $88.0 \% \pm 4.9 \%$; stented xenograft, $90.0 \%$ $\pm 8.0 \% ; P=.4$ ) for all study groups at 7 years. No patient undergoing the Ross procedure required reoperation for pulmonary homograft stenosis. When assessing combined freedom from all valve-related morbidity and cardiac mortality, differences were observed among groups (Freestyle, $66.1 \%$, homograft, $83.9 \%$; stented xenograft, $77.8 \%$; Ross procedure, $86.0 \%$ ), although they were not significant at 7 years (Ross procedure vs stented xenograft, $P=.14$; Ross procedure vs Freestyle, $P=.26$; Ross procedure vs homograft, $P=.28$ ).

\section{Functional Class Assessment and Valve Performance} For all yearly follow-up, freedom from functional class III and IV was greater than $95 \%$ and comparable for all groups. At 6 months postoperatively, the indexed effective valve orifice area had increased in all groups (Freestyle, $1.0 \pm 0.3$ $\mathrm{cm}^{2} / \mathrm{m}^{2}$; homograft, $1.4 \pm 0.3 \mathrm{~cm}^{2} / \mathrm{m}^{2}$; stented xenograft, $0.9 \pm 0.2 \mathrm{~cm}^{2} / \mathrm{m}^{2}$; Ross procedure, $1.5 \pm 0.4 \mathrm{~cm}^{2} / \mathrm{m}^{2}$ ) but remained significantly higher in the Ross procedure and homograft groups compared with the Freestyle or stented xenograft groups $(P<.0001)$. Similarly, mean transvalvular gradients decreased in all groups and continued to be significantly lower in the Ross procedure and homograft groups (Freestyle, $8.6 \pm 5.2 \mathrm{~mm} \mathrm{Hg}$; homograft, $4.4 \pm 3.3$ $\mathrm{mm} \mathrm{Hg}$; stented xenograft, $13.0 \pm 6.3 \mathrm{~mm} \mathrm{Hg}$; Ross procedure, $\left.3.0 \pm 2.7 \mathrm{~cm}^{2} / \mathrm{m}^{2} ; P<.0001\right)$. Subsequently, he- modynamic performance remained stable throughout the study period for all groups. Only 3 patients showed significant aortic regurgitation at follow-up ( $\geq$ class III-IV/IV). One patient in the Freestyle group required reoperation 5.5 years after the initial implantation, 1 patient in the stented xenograft group experienced an early prosthetic endocarditis necessitating reoperation, and 1 patient in the Ross procedure group is currently being followed for ongoing class III-IV autograft regurgitation 10 years postoperatively.

\section{Discussion}

The ideal biologic valve should show good hemodynamic characteristics, be easy to implant, and demonstrate excellent durability with minimal valve-related complications. Reports assessing the long-term outcomes of stented porcine or bovine pericardial valves for patients older than 65 years show excellent valve durability with low valve-related complications. ${ }^{9,10}$ On the other hand, durability of biologic valves in younger patients has been reported to be inversely related to age at implantation. ${ }^{11}$ Comparison of outcomes for currently available biologic valves in middle-aged patients (45-65 years) requiring aortic valve replacement remain sparse. The present study, from a single high-volume center, reports results comparing midterm outcomes of currently available biologic valves for the 45- to 65-year-old patient choosing a biologic prosthesis for aortic valve replacement. Results show comparable cardiac-related survival. Valve-related morbidity, including structural valve dysfunction, was low for all valve types. Although hemodynamic performance was enhanced in patients with a Ross or homograft procedure, freedom from functional class III or IV on follow-up was high and comparable for all groups.

Because of their excellent durability, mechanical valves have been the mainstay of aortic valve replacement for young and middle-aged patients. ${ }^{12,13}$ However, thromboembolic complications, anticoagulation-related complications, tissue pannus ingrowth, and endocarditis plague the longterm outcome of mechanical valves. Furthermore, studies have shown comparable long-term survival between mechanical and bioprosthetic aortic valves. ${ }^{14}$ Unileaflet tilting disc valves have been supplanted by their bileaflet counterparts. Complication rates among current bileaflet disc valves are similar. ${ }^{15,16}$ In an attempt to decrease thrombogenicity, new prosthesis designs, such as the pure carbon On- $X$ valve, have failed to decrease the incidence of thromboembolic events in at least one study. ${ }^{17}$ Moreover, bleeding events related to lifelong anticoagulation with mechanical valves remain a significant source of morbidity. Bleeding complications are increased in elderly patients, and higher levels of international normalized ratio (INR) are seen. ${ }^{18,19}$ Reports assessing ranges of INR have shown up to $40 \%$ of INR levels to be out of the recommended range. ${ }^{20}$ 
As opposed to mechanical valves, biologic valves obviate use of coumadin-based anticoagulation. Although durability remains the main limitation to implantation of biologic valves in younger patients, the current midterm report did not delineate significant differences among currently available biologic valves for the 45- to 65-year old age group. In addition to valve durability and valve-related complications, other patient- and valve-related variables, such as patient comorbidities and valvular cause, ease of implantation and reoperation, and prosthesis characteristics and availability, have to be taken into account when evaluating the type of biologic valve to implant in a middle-aged patient. Patients requiring aortic valve replacement at a younger age show decreased long-term survival compared with a matched undiseased population, mainly because of the presence of comorbidities, such as concomitant coronary artery disease or cardiomyopathy. ${ }^{21}$ Such comorbidities are important considerations in the decision-making process to implant a biologic valve at a younger age.

Considering differences in the risk profile between groups, the present study shows similar perioperative mortality and morbidity for the 4 types of biologic valves, although the level of implantation complexity differs among the valve types, as suggested by the increased cardiopulmonary bypass and crossclamp times in the homograft, Freestyle, and Ross procedure groups. Excellent perioperative results have also been reported by other high-volume centers dedicated to complex root-reconstruction procedures. ${ }^{22,23}$ However, stentless valves, the Ross procedure, and allograft implantation are known to be associated with a significant number of technical pitfalls that might affect early outcome. ${ }^{24}$

Considering the high probability of reoperation when implanting biologic valves in younger patients, risks of reoperation according to valve type must be evaluated. With increasing experience and enhanced myocardial preservation techniques, mortality for reoperative aortic valve replacement has been reported to be as low as $1.2 \%$ for stented xenografts. ${ }^{21}$ On the other hand, root reintervention in a calcified homograft remains a challenging operation that might incur significant complications. Although not encountered in the present study, immunologic mediated pulmonary homograft stenosis or autograft failure caused by root dilatation have been reported as a significant cause of failure after the Ross procedure. ${ }^{25,26}$ In a study comprising a limited number of patients, Lucian and colleagues ${ }^{27}$ have reported a significantly higher mortality for reoperative operations of stentless valves compared with stented bioprostheses.

Valve performance was significantly enhanced in the homograft and Ross procedure groups. However, the effect of valve performance on patient survival or functional status is highly debated. ${ }^{28,29}$ Within the present study, no significant advantage on functional class outcome was observed with the homograft or Ross procedure. However, recent studies have demonstrated the importance of avoiding severe mismatch in patients undergoing aortic valve replacement, especially in the presence of left ventricular dysfunction. ${ }^{30,31}$ Although a rare clinical setting, when encountering a small aortic root with a potential to induce a severe mismatch, selection of a biologic valve with a better hemodynamic profile or performance of a root-enlargement procedure should be considered. Selection of the type of biologic valve might also be influenced by valve pathology. Homografts, because of their low risk of reinfection and flexibility in implantation technique, comprise an excellent conduit in the presence of active endocarditis. However, homograft availability remains sparse, and valve durability might be influenced by delay in graft procurement, donor age, graft quality, and host immunologic response. ${ }^{32,33}$

Although this study represents one of few reports comparing biologic aortic valves in the middle-aged patient, study limitations should be addressed. The present study is limited to midterm results, and longer follow-up will possibly allow better delineation of the rate of valve failure, as well as the mode of such failures. Future studies assessing the benefits of biologic valves in young patients will have to take into account the risks of reoperation compared with the risks of long-term anticoagulation. Recently, Gaudiani and associates, ${ }^{34}$ using a risk model, showed the risks of reoperation with biologic valves to be comparable with the long-term risks of anticoagulation. Furthermore, development of selfmanagement INR-monitoring strategies might result in a decrease in anticoagulation-mediated morbidity and limit the benefits of use of biologic valves in younger patients. ${ }^{35,36}$ Similarly, the burden of anticoagulationmediated morbidity in patients with mechanical valves might also be decreased through investigation of new anticoagulant agents, such as ximelagatran, a direct thrombin inhibitor. ${ }^{37}$ On the other hand, development in the field of biologic valves, such as tissue heart valve engineering, might offer new strategies to increase valve durability. ${ }^{38}$

In conclusion, current available biologic valves show comparable outcomes at midterm for the 45- to 65-year-old patient choosing a biologic valve for aortic valve replacement. Until long-term comparative studies are available, selection of a biologic valve for the 45- to 65-year-old patient should also take into account patient characteristics and comorbidities, ease of valve implantation and reoperation, and surgical expertise. Developments in tissue valve engineering and anticoagulation regimens will probably affect the decision-making process in terms of valve selection 
for the middle-aged patient requiring aortic valve replacement in the near future.

\section{References}

1. Kouchoukos NT, Davila-Roman VG, Spray TL, Murphy SF, Perrillo JB. Replacement of the aortic root with a pulmonary autograft in children and young adults with aortic-valve disease. $N$ Engl J Med. 1994;330:1-6.

2. Pessotto R, Wells WJ, Baker CJ, Luna C, Starnes VA. Midterm results of the Ross procedure. Ann Thorac Surg. 2001;71(suppl):S336-9.

3. Elkins RC, Lane MM, McCue C. Ross operation in children: late results. J Heart Valve Dis. 2001;10:736-41.

4. Chang BC, Lim SH, Kim DK, Seo JY, Cho SY, Shim WH, et al. Long-term results with St-Jude Medical and Carbomedics prosthetic heart valves. J Heart Valve Dis. 2001;123:715-23.

5. Zellner JL, Kratz JM, Crumbley AJ 3rd, Stroud MR, Bradley SM, Sade RM, et al. Long-term experience with the St-Jude Medical valve prosthesis. Ann Thorac Surg. 1999;68:1210-8.

6. Jamieson WR, Ling H, Burr LH, Fradet GJ, Miyagishima RT, Janusz MT, et al. Carpentier-Edwards supraannular porcine bioprosthesis evaluation over 15 years. Ann Thorac Surg. 1998;66(suppl):S49-52.

7. Glower DD, Landolfo KP, Cheruvu S, Cen YY, Harrison JK, Bashore $\mathrm{T}$, et al. Determinants of 15-year outcome with 1,119 standard Carpentier-Edwards porcine valves. Ann Thorac Surg. 1998;66(suppl): S44-8.

8. Edmunds LH Jr, Clark RE, Cohn LH, Grunkemeier GL, Miller DC, Weisel RD. Guidelines for reporting morbidity and mortality after cardiac valvular operations. Ann Thorac Surg. 1996;62:932-5.

9. Jamieson WR, Janusz MT, Burr LH, Ling H, Miyagishima RT, Germann E. Carpentier-Edwards supraannular porcine bioprosthesis: second-generation prosthesis in aortic valve replacement. Ann Thorac Surg. 2001;71(suppl):S224-7.

10. Poirier NC, Pelletier LC, Pellerin M, Carrier M. 15-year experience with the Carpentier-Edwards pericardial bioprosthesis. Ann Thorac Surg. 1998;66(suppl):S57-61.

11. Banbury MK, Cosgrove DM 3rd, Lytle BW, Smedira NG, Sabik JF, Saunders CR. Long-term results of the Carpentier-Edwards pericardial aortic valve: a 12-year follow-up. Ann Thorac Surg. 1998;66(suppl): S73-6.

12. Gott VL, Alizo DE, Cameron DE. Mechanical heart valves: 50 years of evolution. Ann Thorac Surg. 2003;76(suppl):S2230-9.

13. Akins CW. Results with mechanical cardiac valvular prostheses. Ann Thorac Surg. 1995;60:1836-44.

14. Hammermeister KE, Sethi GK, Henderson WG, Oprian C, Kim T, Rahimtoola S. A comparison of outcomes in men 11 years after heart-valve replacement with mechanical valve or bioprosthesis. N Engl J Med. 1993;328:1289-96.

15. Walther T, Falk V, Tigges R, Kruger M, Langebartels G, Diegeler A, Autschbach R, et al. Comparison of On-X and SJM HP bileaflet aortic valves. J Heart Valve Dis. 2000;9:403-7.

16. Lim KH, Caputo M, Ascione R, Wild J, West R, Angelini GD, et al. Prospective randomized comparison of CarboMedics and St-Jude Medical bileaflet mechanical heart valve prosthesis: an interim report. J Thorac Cardiovasc Surg. 2002;123:21-32.

17. Laczkovics A, Heidt M, Oelert H, Laufer G, Greve H, Pomar JL, et al. Early clinical experience with the On-X prosthetic heart valve. J Heart Valve Dis. 2001;10:94-9.

18. Vink R, Kraaijenhagen RA, Hutten BA, van den Brink RB, de Mol BA, Buller HR. Management of anticoagulant therapy for patients with prosthetic heart valves or atrial fibrillation. Hematology. 2004;9:1-9.

19. Milano A, Guglielmi C, De Carlo M, Di Gregorio O, Borzoni G, Verunelli $\mathrm{F}$, et al. Valve-related complications in elderly patients with biological and mechanical aortic valves. Ann Thorac Surg. 1998; 66(suppl):S82-7.

20. Kortke H, Korfer R. International normalized ratio self-management after mechanical heart valve replacement: is an early start advantageous? Ann Thorac Surg. 2001;72:44-8.
21. Svensson LG, Blackstone EH, Cosgrove DM. Surgical options in young adults with aortic valve disease. Curr Probl Cardiol. 2003;28: 417-79.

22. Alphonso N, Baghai M, Dhital K, Mood G, Tulloh R, Austin C, et al. Midterm results of the Ross procedure. Eur J Cardiothorac Surg. 2004;25:925-30

23. Elkins RC. The Ross operation: a 12-year experience. Ann Thorac Surg. 1999;68(suppl):S14-8.

24. Sirvydis V, Sudikiene R, Lebetkevicius V. Ross operation-immediate and mid-term results. Cardiovasc Surg. 2000;8:555-60.

25. Raanani E, Yau TM, David TE, Dellgren G, Sonnenberg BD, Omran A. Risk factors for late pulmonary homograft stenosis after the Ross procedure. Ann Thorac Surg. 2000;70:1953-7.

26. David TE, Omran A, Ivanov J, Armstrong S, de SA MP, Sonnenberg B, et al. Dilation of the pulmonary autograft after the Ross procedure. J Thorac Cardiovasc Surg. 2000;119:210-20.

27. Lucian GB, Casal G, Auriemma S, Santin F, Mazzucco A. Survival after stentless and stented xenograft antivalve replacement: a concurrent, controlled trial. Ann Thorac Surg. 2002;74:1443-9.

28. Gelsomino S, Morocutti G, Masullo G, Da Col P, Frassani R, Spedicato L, et al. Patient-prosthesis mismatch after small-size stentless aortic valve replacement. J Card Surg. 2004;19:91-7.

29. Freed DH, Tam JW, Moon MC, Harding GE, Ahmad E, Pascoe EA. Nineteen-millimeter prosthetic aortic valves allow normalization of left ventricular mass in elderly women. Ann Thorac Surg. 2002;74: 2022-5.

30. Blais C, Dumesnil JG, Baillot R, Simard S, Doyle D, Pibarot P. Impact of valve prosthesis-patient mismatch on short-term mortality after aortic valve replacement. Circulation. 2003;108:983-8.

31. Ruel M, Rubens FD, Masters RG, Pipe AL, Bedard P, Hendry PJ, et al. Late incidence and predictors of persistent or recurrent heart failure in patients with aortic prosthetic valves. J Thorac Cardiovasc Surg. 2004;127:149-59.

32. Yacoub M, Rasmi NR, Sundt TM, Lund O, Boyland E, Radley-Smith $\mathrm{R}$, et al. Fourteen-year experience with homovital homografts for aortic valve replacement. J Thorac Cardiovasc Surg. 1995;110:18693.

33. Takkenberg JJ, van Herwerden LA, Eijkemans MJ, Bekkers JA, Bogers AJ. Evolution of allograft aortic valve replacement over 13 years: results of 275 procedures. Eur J Cardiothorac Surg. 2002;21: 683-91.

34. Gaudiani VA, Grunkemeier GL, Castro LJ, Fisher AL, Wu Y. The risks and benefits of reoperative aortic valve replacement. Heart Surg Forum. 2004;7:E170-3.

35. Sawicki PT. A structured teaching and self-management program for patients receiving oral anticoagulation: a randomized controlled trial. Working Group for the Study of Patient Self-Management of Oral Anticoagulation. JAMA. 1999;281:145-50.

36. Siebenhofer A, Berghold A, Sawicki PT. Systematic review of studies of self-management of oral anticoagulation. Thromb Haemost. 2004; 91:225-32.

37. Salam AM, Al-Mousa EN. The therapeutic potential of ximelagatran to become the anticoagulant of choice in medicine: a review of recently completed clinical trials. Expert Opin Pharmacother. 2004; 5:1423-30

38. Mol A, Bouten CV, Baaijens FP, Zund G, Turina MI, Hoerstrup SP. Tissue engineering of semilunar heart valves: current status and future developments. J Heart Valve Dis. 2004;13:272-80.

\section{Discussion}

Dr W. R. Eric Jamieson (Vancouver, British Columbia, Canada). Dr Dagenais, I congratulate you on a very excellent topic. This is a difficult group of patients, and the decision of which valve to implant is a difficult one. There are obviously certain limitations to the study because of the numbers and complexity of the various procedures, but I think it is extremely important that we discuss this. I have about 7 short questions related to this particular topic.

It appears that your longest experience comes with the Ross and the Freestyle, of which you were part of the regulatory trial, 
and our beloved colleague, Dr Cratier, who died untimely, did a lot of these Ross procedures. Do you believe that there has been a change in your pattern of practice toward the homograft and the stented xenograft, and if so, for what reason?

Dr Dagenais. Yes, we had changes in terms that we possibly do less Ross procedures in the 45- to 65-year-old patient, and now we use more stented xenografts. We decided to do this study because we had no true decision making in these patients.

Dr Jamieson. My other questions relate to the homograft. You $\operatorname{did} 85 \%$ roots, and in the Freestyle group your roots were $21 \%$. As to the homograft experience, were there a lot of cases of endocarditis while you were using the root?

Dr Dagenais. I think there were only 3 cases of endocarditis in this study, and that is why we included them.

Dr Jamieson. Do you have concern about the future with regard to root homografts? You know all these patients potentially are going to get a second operation and maybe a third in their lifetimes, but the calcification of the homograft root and the potential with the root replacement in the Freestyle, amino oleic acid being very effective on the leaflets but not quite as effective on the wall. What are your thoughts of the future there, and how are you doing surveillance on these patients?

Dr Dagenais. What I think this study shows is that at least at midterm and until we have further data on the long-term durability of these different conduits, the ease of reoperation has to be taken into account, and doing a reoperation in a calcified root or with the root Freestyle is much more difficult than doing a redo stented xenograft. I think that is one of the take-home messages of this study.

Dr Jamieson. There has been a lot written on bicuspid aortic valves and valvular pathology in the pulmonary valve and the pulmonary root and the concept of annular dilatation, and our Canadian colleague, Dr Tirone David, has written extensively on that topic as well. I do not believe you have identified any of those problems here, but can you tell us any of your observations or concerns?

Dr Dagenais. With annular dilatation with our experience in the Ross group, we tried to avoid doing Ross procedures in those patients. In this study we had no reoperation for the pulmonary homograft because we used the biggest available pulmonary homograft on the shelf. We have learned this through our early experiences in younger patients, and I think that is also supported in the literature.

Dr Jamieson. The concept of patient-prosthesis mismatch, as popularized by your cardiologist colleagues, is designated with indexed effective orifice area less than $0.85 \mathrm{~cm}^{2} / \mathrm{m}^{2}$. You identified that there is some element of mismatch in your stented prosthesis and even your stentless prosthesis. We have identified, along with your center, that in elderly persons some degree of mismatch does not influence mass reduction and does not influence survival. Do you think in this particular age group of more active people with aerobic activity that some element of mismatch might be important? If that is the case, the Ross procedure is a very important procedure to perform over the other stented or even stentless procedures.

Dr Dagenais. Well, I think as we showed in this study, functional class was not influenced by valve performance. However, I think one has to realize also that the mismatch in this cohort, especially in the stented xenograft and the Freestyle groups, was about $30 \%$. Most of the mismatches were between 0.75 and 0.85 . Thus I think with mild mismatch, we will not see any effect on survival or functional class. However, I think if you go under 0.75 , then I think we have to really watch out in this young subgroup not to have problems with mismatch.

Dr Jamieson. Just 2 other questions. In your final surveillance, your surveillance of the heterografts, you have used 2 valves. Both have different failure modes. The Mosaic, if it is going to fail (some calcification, tear), the patient becomes symptomatic from insufficiency. The Perimount predominantly fails $85 \%$ by calcification, and these patients experience insipient stenosis. What is your surveillance pattern or what are you doing to observe these because you are putting these heterografts in a population in which they can be subjected to early degeneration?

Dr Dagenais. All these patients are followed initially with a clinical visit every year and an echocardiogram every 2 years if everything is stable, and therefore they are followed pretty closely, and I think one should have such a follow-up in these patients to be able to have a good long-term follow-up.

Dr Edward Verrier (Seattle, Wash). I have a couple of brief questions. The striking data in this are first that the freedom from reoperation is lowest in the Ross procedure. As we know from the data in the Ross registry, that procedure reached its heyday in the mid-1990s and has certainly steadily decreased in use, both because of the high operative mortality that approaches $4 \%$ and the need for reoperation that approaches $10 \%$ over 8 years for the pulmonary homograft. Do your data include all reoperations on the pulmonary homograft or just the autograft?

Dr Dagenais. As I discussed, pretty surprisingly in this cohort of patients, no patients required reoperation for their pulmonary homograft. We have had that in our younger patients but not in this cohort of patients, possibly because we started to do the Ross procedure in a younger age group, and now we know that we have to use the largest pulmonary homograft conduit available.

Dr Verrier. That certainly would go against what a lot of other persons reported. The second interesting issue is the reduced 7 -year survival benefits with the Freestyle group at $71 \%$ and the stented group at $87 \%$ compared with the homograft or Ross groups. First, this would certainly go against the Toronto experience, which stated a significant survival benefit with the stentless valve versus the stented valve technology. Is this a selection bias or an age bias, or from your data, even though the numbers are low, do you think that you refute this intermediate survival benefit with the stentless technology?

Dr Dagenais. Well, I think one has to look into the limitations of the study. I think age is a very important factor, and I think that is why we took the cardiac survival because we had 32 deaths during the follow-up period, 18 of which were of noncardiac cause and 14 of which were in the Freestyle group. Therefore I think when you take out those noncardiac deaths with the limitation of the study, you find that there is no difference between survival among groups. Now does this go against the Toronto series in terms of increasing midterm survival? We will have to address this issue with a longer follow-up. I personally think that with the current data on stentless valves, it is difficult yet to find a survival advantage over stented xenograft valves. 
Dr Verrier. Thank you. I also think the effect of the reoperation that occurs cannot be understated because certainly most of us have abandoned the homograft except in endocarditis because when you have to reoperate on a calcified root in a young person, it is one of the most daunting operations we perform.

Dr Dagenais. I totally agree.

Dr D. Craig Miller (Stanford, Calif). Francois, nice presentation, but I cannot let you get away with censoring all these "noncardiac deaths." I know you did not have autopsies, or did you? How do you know that those 18 deaths, a lot of which were probably sudden and unexplained, were not of a cardiac cause? That has been a bugaboo in any valve series, and the only way to conservatively approach it is to consider them all, knowing that you are probably overestimating the incidence of cardiac death, but at least you are not letting something that smells bad creep into your data. What would those curves look like with all deaths?

Dr Dagenais. We are the only center to which 3 million persons are referred, and we have 2 nurses who are truly dedicated to follow these patients. Most of these patients have autopsies when they die. I think in such circumstances it is difficult to keep the noncardiac deaths in the analysis considering the age difference between the groups. This is, however, a study limitation. When you include the noncardiac deaths, there was a trend toward lower survival in the Freestyle and the stented xenograft groups.

\section{ON THE MOVE?}

Don't miss a single issue of the journal! To ensure prompt service when you change your address, please photocopy and complete the form below.

Please send your change of address notification at least six weeks before your move to ensure continued service. We regret we cannot guarantee replacement of issues missed due to late notification.

\section{JOURNAL TITLE:}

Fill in the title of the journal here.

OLD ADDRESS:

Affix the address label from a recent issue of the journal here.

\section{NEW ADDRESS:}

Clearly print your new address here.

Name

Address

City/State/ZIP
COPY AND MAIL THIS FORM TO:

Elsevier Inc.

Subscription Customer Service

6277 Sea Harbor Dr

Orlando, FL 32887
OR FAX TO:

407-363-9661

OR E-mail:

elspcs@elsevier.com
OR PHONE:

800-654-2452

Outside the U.S., call

407-345-4000 